This is the accepted manuscript of the paper published in Solar Energy (Volume 135, October 2016, Pages 471-478), doi: 10.1016/j.solener.2016.06.014, C 2016 Elsevier Ltd.

\title{
Maximum-power-point tracking during outdoor ageing of solar cells
}

\author{
Marko Berginc*, Boštjan Glažar, Marko Topič \\ *corresponding author \\ University of Ljubljana, Faculty of Electrical Engineering \\ Tržaška cesta 25, SI-1000 Ljubljana, Slovenia \\ (E-mails: marko.berginc@,fe.uni-lj.si, bostjan.glazar@,fe.uni-lj.si, marko.topic@,fe.uni-lj.si)
}

\begin{abstract}
:
This paper describes how to select a passive load which would the most accurately follow the maximum-power-point (MPP) of small laboratory size solar cells installed outdoors in Central Europe. Either resistor or diode type of passive load have been used as a low-cost alternative to active MPP trackers (designed especially for a long-term outdoor stability study of different types of small size laboratory solar cells). The dye-sensitized solar cells have been chosen as a representative case since they exhibit similar current-voltage $(I-V)$ characteristics dependence at different light intensities $(G)$ and cell temperatures $\left(T_{C}\right)$ as other solar cell's technologies. The results showed that the most efficient tracking was achieved when the $I-V$ characteristic of the optimal resistor or diode cross the MPP of the solar cell measured at $G=73 \mathrm{~mW} / \mathrm{cm}^{2}$ and $T_{\mathrm{C}}=25^{\circ} \mathrm{C}$. A significantly better tracking could be obtained when instead of a resistor an optimal diode is used; the optimal diode consumes $96.5 \%$ of the annual energy that would be potentially produced by the solar cell connected to ideal MPP tracker while the optimal resistor consumes only $83.5 \%$ of that energy.
\end{abstract}

Keywords: solar cells, maximum-power point, MPP tracking, energy yield, diode, resistor

\section{Introduction}

In recent years emerging solar cell technologies (dye-sensitized solar cells DSSCs [1-4], organic solar cells [5-7], etc.) and concepts (plasmonic [8-15], quantum dots [16-17], etc.) have been studied with an aim to improve cell performance and stability. In addition, solar cells that employ halide perovskite absorbers like $\mathrm{CH}_{3} \mathrm{NH}_{3} \mathrm{PbI}_{3}$ have emerged from the field of DSSCs. This novel solar cell technology attracted perceivable attention as a low cost and efficient technology with record efficiencies currently exceeding $20 \%$ [7, 18-20] but full device stability still needs to be proven [19, 21-24]. In general the stability of the solar cells is confirmed after several indoor stress tests are passed. However the long-term outdoor tests are also frequently examined since important information about the stability under real operating conditions might be revealed $[25,26]$. This raises a question which load should be applied to the solar cells during the ageing since the operation condition is expected to influence the degradation as well [26]. The short-circuit and open-circuit conditions can be easily obtained but under these conditions the solar cells do not generate any power. On the other hand the degradation under maximum-power-point (MPP) condition is the most relevant since this is a condition where solar cells normally operate. However, the MPP of an individual solar cell is difficult to follow due to constantly changing weather conditions (cell temperature $-T_{C}$, light intensity $-G$ ) and ageing. Normally, active MPP trackers should be employed to follow the actual MPP by constantly adjusting the electronic load [27, 28], but since MPP tracking operates on an individual solar cell, an ageing study with a batch of samples would require numerous low-power active MPP trackers that should be custom designed and build for small-size laboratory cells. Alternatively, a passive load may be used and a fixed resistor or (Schottky) diode(s) could be used as practical solutions to follow the MPP condition of an 
individual cell during outdoor testing under changing weather (air temperature $T_{A I R}, G$ ). Such tracking may not be ideally perfect since both, resistor and diode are passive elements. Therefore it is very important to know how to choose the most appropriate value and this is the subject of the present paper. For our analysis we used typical ionic-liquid based DSSCs. We developed the $T_{C}$ and $G$ depended current-voltage ( $\left.I-V\right)$ model of the DSSC first and in a combination with the set of one year weather data $\left(T_{A I R}, G\right)$ we calculated the energy yields of the DSSC in Ljubljana (Central Europe) when the cell is loaded with different passive loads (i.e. resistors $\mathrm{R}$ or diodes $\mathrm{D}$ ). Further on we describe how to choose the optimal $\mathrm{R}$ or diode $\mathrm{D}$ in order to obtain the most efficient annual tracking, i.e. the highest annual energy yield of the solar cell. Finally the MPP tracking error for different operating conditions $\left(T_{C}, G\right)$ is given if the optimal resistor or diode is connected to the solar cell.

\section{Experimental}

\subsection{Manufacturing of DSSCs}

The manufacturing process of the DSSC is shown in Fig. 1. A fluorine-doped $\mathrm{SnO}_{2}$ coated glass (i.e. transparent conductive oxide, TCO) with a sheet resistance of $8 \Omega / \square$ was used for the front and back cell substrate. An optimized Pechini sol-gel $\mathrm{TiO}_{2}$ paste (based on $\mathrm{P} 25$, Degussa) [29] was then applied to the surface of the front TCO glass substrate using a "doctor blading" technique to form a rectangular pad of $\mathrm{TiO}_{2}$ with an area ranging from 0.58 to $0.68 \mathrm{~cm}^{2}$. The $\mathrm{TiO}_{2}$ layer was sintered at $450{ }^{\circ} \mathrm{C}$ for one hour before being immersed for 12 hours in an ethanol solution of a Ruthenium complex based dye N719 (Ru(2,2'bipyridyl4,4'dicarboxylate) 2 (NCS)2, Solaronix). For a counter electrode, platinum (thickness $\sim 5 \mathrm{~nm}$ ) was sputtered onto the back TCO glass substrate. The active and counter electrodes were then sealed using $25 \mu \mathrm{m}$ thick polymer foil frame (Surlyn, DuPont) which also acts as a spacer between the electrodes. The electrolyte is a binary ionic-liquid mixture in a volume ratio 13:7 of 1-propyl-3-methyl-imidazolium iodide (Iolitec) and 1-ethyl-3-methyl-imidazolium tetracyanoborate (Merck), with addition of $0.5 \mathrm{M} \mathrm{N}$-methylbenzimidazol, $0.1 \mathrm{M}$ guanidinium thiocyanate and $0.2 \mathrm{M}$ of $\mathrm{I}_{2}$; the composition which remains as the best binary ionic liquid electrolyte for DSSCs [29]. After injecting the electrolyte through two pre-drilled holes in the counter electrode we sealed the cells and stored them in the dark for 24 hours to allow a complete penetration of electrolyte into the $\mathrm{TiO}_{2}$ pores. The whole manufacturing was processed by hand which caused some variations in active areas and performances.

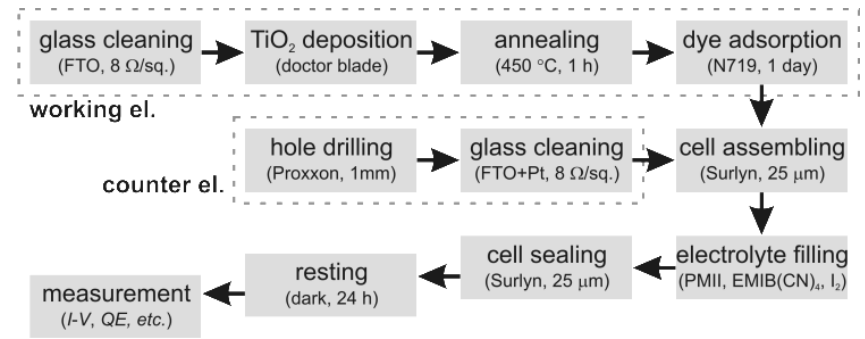

Fig. 1 Manufacturing of dye-sensitized solar cells.

\subsection{Characterization}

\subsubsection{Indoor characterization}

The $I-V$ characterization was performed using an Oriel Class ABA solar simulator equipped with a $1.5 \mathrm{G}$ air mass filter, the spectrum of which closely matches the required AM1.5 spectrum. In accordance with the IEC60904-3 standard the short-circuit current mismatch 
parameter was calculated and in conjunction with a calibrated crystalline silicon c-Si reference solar cell, covered with a KG5 glass filter, the level of standard illumination $\left(100 \mathrm{~mW} / \mathrm{cm}^{2}\right)$ was determined. The light intensity was reduced using different neutral density filters (Melles Griot) which had only a negligible influence on the illumination spectrum up to $800 \mathrm{~nm}$. Regardless of the light intensity we used a calibrated c-Si reference solar cell equipped with a KG5 glass filter to determine a specific $G$. A cooling/heating Peltier element was used to stabilize different $T_{C}$ including the $25^{\circ} \mathrm{C}$. Before characterization, each cell was placed and secured with a contact tip to a copper plate to assure a good electrical and thermal contact. The cell was then covered by a Styrodur box to insulate it from the heat produced by the solar simulator. The $T_{C}$ was determined as an average reading of two negative temperature coefficient resistors (NTCs) before and after the measurement; one NTC resistor was placed into the upper copper plate and the other directly onto the glass of the cell. When the temperatures of both NTC resistors equalized and the temperature inside the box stabilized, we removed the box and performed the measurement at certain $G$ and $T_{C}$. During the characterization we also masked the cells to leave only the active area of the cell exposed, which is stated as the most rigorous condition regarding the cell's efficiency. The $I-V$ characteristics of the cells were then measured using a Keithley 238 source meter by applying a voltage and measuring the current. The cells were scanned stepwise $(10 \mathrm{mV})$ from $0 \mathrm{~V}$ (short-circuit condition) to $0.9 \mathrm{~V}$ (beyond open-circuit voltage $V_{O C}$ ).

\subsubsection{Outdoor characterization}

Outdoor ageing was performed on the roof of the Faculty of Electrical Engineering, University of Ljubljana (latitude $46^{\circ} 2^{\prime} 39.39^{\prime \prime} \mathrm{N}$, longitude $14^{\circ} 29^{\prime} 18.28^{\prime \prime} \mathrm{E}$ [26]) for 7 months (April-October). Cumulatively the DSSCs were exposed to $906 \mathrm{kWh} / \mathrm{m}^{2}$ irradiation. The cells were stored in a water proof container with a transparent cover (total transmission ranges between 88 and $90 \%$ and total reflection between 5 and $10 \%$ in the visible wavelength range). Each of the six cells in the batch were then divided into two groups and aged under the (i) quasi maximum-power-point using a shunt resistor (approximately $100 \Omega$ ), Fig. 2A and (ii) quasi maximum-power-point using two Schottky diodes and $1 \Omega$ shunt resistor in series, Fig. 2B. The in-house built temperature compensated 24-bit data logger stored in the waterproof container was used to measure the voltages across the shunt resistors in-situ every 10 minutes which allowed the calculation of the current and the voltage at the quasi maximum-power point ( $I_{M P P}$ and $V_{M P P}$, respectively) at the later stage. During the 7 months outdoor testing the $T_{C}$ were measured using integrated digital temperature sensors (Dallas Semiconductors). Additionally the $G$ and $T_{A I R}$ were measured every 10 minutes throughout the same year. A calibrated reference pyranometer CMP 6 (Kipp\&Zonen) was used to determine the $G$ in the plane of the samples and a weather station (La Crosse Technology, WS3600) for monitoring the $T_{A I R}$.
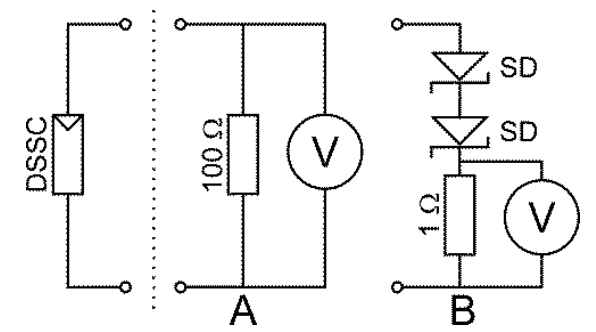

Fig. 2 Electric circuits used for MPP tracking of the DSSC with (A) resistor ( $R=100 \Omega$ ) or (B) two Schottky diodes (SD) and a small shunt resistor $(R=1 \Omega)$ connected in serial. 
This is the accepted manuscript of the paper published in Solar Energy (Volume 135, October 2016, Pages 471-478), doi: 10.1016/j.solener.2016.06.014, C 2016 Elsevier Ltd.

\section{Results and discussion}

In Section 3 we deal with the output power of the small size laboratory solar cell (in our study DSSC) during annual outdoor testing when different resistors and diodes, respectively, instead of an active MPP tracking device are connected to the DSSC. In Section 3.1 we define how to choose the most appropriate resistor or diode in order to obtain the most effective tracking, i.e. the highest annual energy yield from the solar cell during outdoor ageing. These optimal values are empirically determined according to developed $I-V\left(G, T_{C}\right)$ model of the DSSC and the $G$ and $T_{C}$ data that were periodically measured over a year. Afterwards, in Section 3.2 we compare the tracking error for different $G$ and $T_{C}$ if the optimal resistor or diode is used.

\subsection{Determination of optimal resistor or diode for the MPP tracking}

Laboratory developed solar cells are usually characterized indoor under standard test conditions STC $\left(100 \mathrm{~mW} / \mathrm{cm}^{2}, 25{ }^{\circ} \mathrm{C}\right)$ by scanning the $I-V$ characteristics since the characteristics reveal a number of important performance parameters (like short-circuit current density $J_{S C}$, open-circuit voltage $V_{O C}$, fill factor $F F$, conversion efficiency $\eta$ ). Especially the $J_{S C}$ is useful and practical parameter for comparison solar cells differing in active areas $\left(A_{C E L L}\right)$ and technologies since the $J_{S C}$ is not dependent on the $A_{C E L L}$. On the other hand it is very difficult to optimize the load according to $J_{S C}$ since the actual loads are usually defined by $I-V$ characteristic and since they are always connected to solar cell having a certain $A_{C E L L}$ and thus generate a certain $I$. Therefore in our study we systematically employ $I=J \cdot A_{C E L L}$ instead of the $J$. Nevertheless, this is just a matter of results presentation and does not influence any conclusion.

Another important parameter in addition to $I_{S C}, V_{O C}, F F$ and $\eta$ is an MPP; a condition where solar cells normally operate as they provide the maximal power to external load. The MPP is defined by the current and voltage pair ( $I_{M P P}$ and $V_{M P P}$, respectively). This $I_{M P P}-V_{M P P}$ pair can be used to choose the appropriate load (e.g. resistor, diode, etc.) to fix the solar cell's operation to the MPP but this holds true as long as operating conditions $\left(G, T_{C}\right)$ do not change and as long as the cell remains stable. However, since the solar cells could be tested outdoor this raises two questions; (i) which load is more appropriate and (ii) how to choose the optimal values of a resistor or diode. In other words which MPP (measured under which $T_{C}$ and $G$ ) should be used to choose the optimal load since the "average" or "typical" outdoor operating conditions differ significantly from indoor STC conditions.
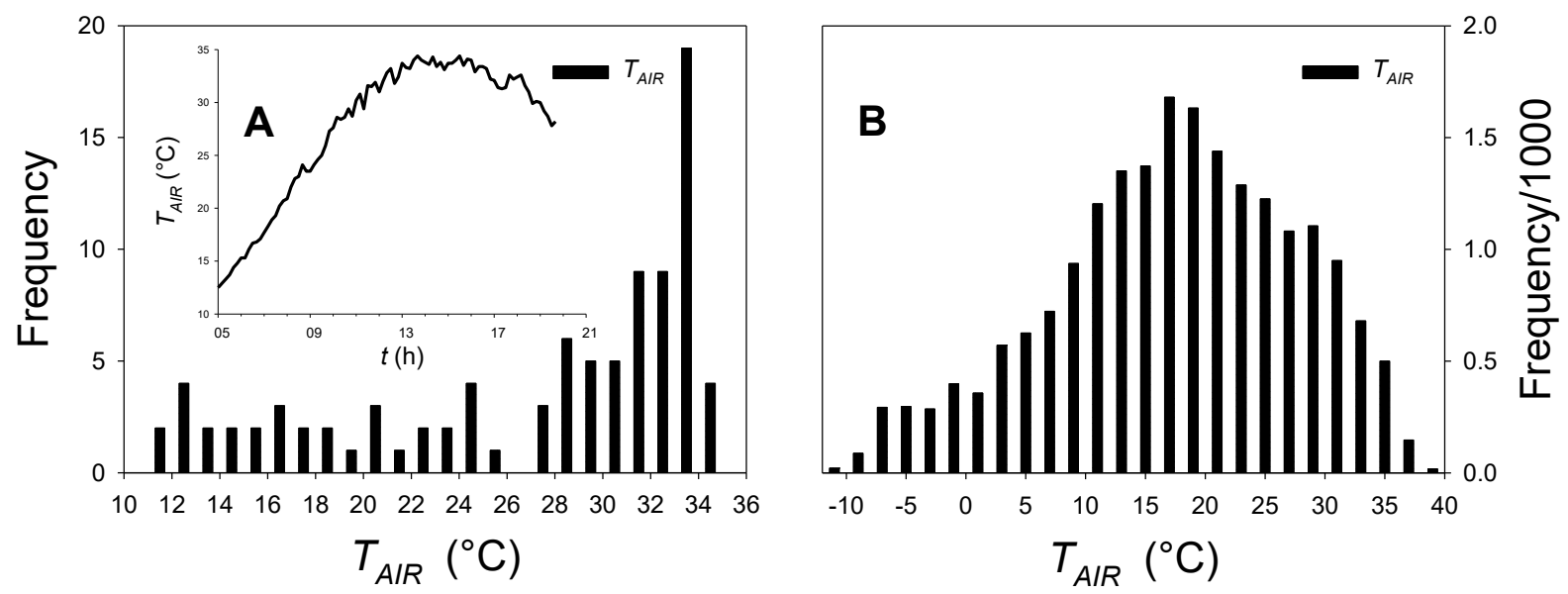
Fig. 3 Histogram of $T_{A I R}$ measured in 10 minutes daytime intervals in Ljubljana sorted for typical sunny day that is given in inset (A) and for a whole year (B).

The progression of $T_{A I R}$ for one typical sunny summer day in Ljubljana is given in inset of Fig. 3A. From the morning till $2 \mathrm{pm}$ the $T_{A I R}$ almost linearly increases from 12 to $34{ }^{\circ} \mathrm{C}$ and decreases gradually afterwards. The lowest $T_{A I R}$ is reached next morning and then it starts increasing again (not shown here). As a result two groups of $T_{A I R}$ could be found in the histogram, Fig 3A; the number of $T_{A I R}$ measurements in the $10{ }^{\circ} \mathrm{C}<T_{A I R}<26{ }^{\circ} \mathrm{C}$ range is relatively small compared to the number of measurements in the $27{ }^{\circ} \mathrm{C}<T_{A I R}<35{ }^{\circ} \mathrm{C}$ temperature range and especially in the $33{ }^{\circ} \mathrm{C}<T_{A I R}<34{ }^{\circ} \mathrm{C}$ range. However, this holds true only for one typical summer day and the conclusions significantly change when a whole year is considered, Fig. 3B. The histogram of the measured $T_{A I R}$ becomes almost Gaussian shaped peaking in 16 to $20^{\circ} \mathrm{C}$ temperature range. Nevertheless, the number of measured $T_{A I R}$ in the 10 to $26^{\circ} \mathrm{C}$ range is also reasonably high therefore a typical annual $T_{A I R}$ could be found within this temperature range.
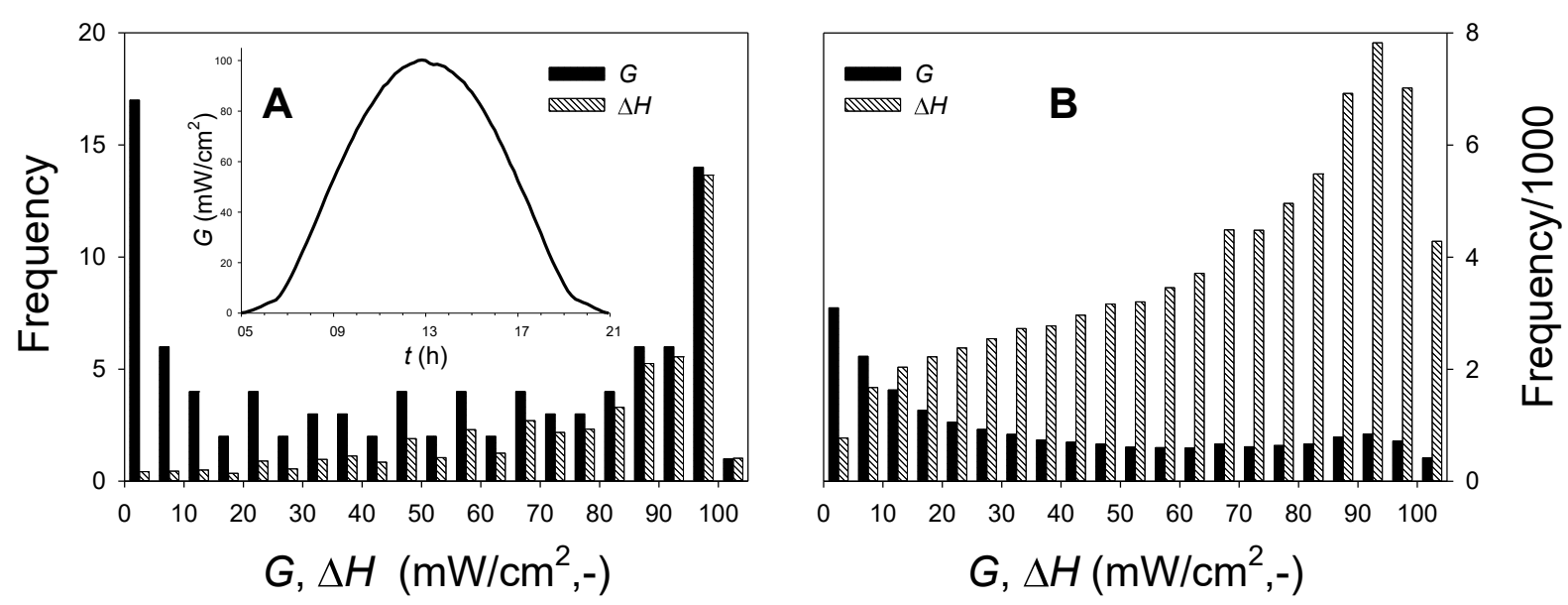

Fig. 4 Histogram of $G$ (black bars) measured in 10 minutes daytime intervals in Ljubljana and normalized histogram (i.e. a frequency of certain $G$ multiplied with that $G$, patterned bars) sorted for typical sunny day that is given in inset (A) and for a whole year (B).

The analysis of $G$ for the same typical sunny day in June in Ljubljana is presented in Fig. 4A. The progression of the daytime $G$ that was measured every 10 minutes follows a semi-cosine law as is shown in the inset of Fig. 4A. This daytime progression has been rearranged to histogram (black columns, Fig. 4A). According to expectation we observe that the most representative and frequent $G$ lies between $0-5 \mathrm{~mW} / \mathrm{cm}^{2}$ or between $95-100 \mathrm{~mW} / \mathrm{cm}^{2}$. Other $G$ does not appear so frequently although the average $G$ for that daytime period equals $46 \mathrm{~mW} / \mathrm{cm}^{2}$. Furthermore, the $G$ that is the most frequently appearing is not necessary the most adequate from the energy yield point of view, e.g. lower $G\left(0-5 \mathrm{~mW} / \mathrm{cm}^{2}\right)$ appears very frequently during the day but the generated energy under this condition is negligible. Therefore it is not important to precisely follow these MPPs and to select the load according to these MPPs. The more appropriate criterium seems frequencies of certain $G$ multiplied with the corresponding $G$, i.e. the normalized histogram $\Delta H$ (patterned bar, Fig. 4A) [30] which more or less increases with increasing $G$ and according to expectation obtain the maximal product in $95<G<100 \mathrm{~mW} / \mathrm{cm}^{2}$ range. However, this conclusion is valid only for sunny days and it significantly changes if partly cloudy, cloudy days and/or rainy days are included. In Fig. 4B we analyse the annual daytime data for $G$ measured in 10 minutes intervals in Ljubljana. The yearly average $G$ equals $39 \mathrm{~mW} / \mathrm{cm}^{2}$ and this value again appears less frequently in the histogram (black bars, Fig. 4B) although much higher frequency in a lower $G$ range and lower frequency in a higher range, relatively, are observed on annual base. 
Therefore the average $G$ nor the most frequent $G$ in the histogram $0<G<5 \mathrm{~mW} / \mathrm{cm}^{2}$ with their corresponding MPPs should be used to determine the optimal load for the solar cells which would provide the most efficient MPP tracking. Furthermore, the frequencies of $G$ multiplied with corresponding $G$, i.e. the normalized histogram (patterned bars, Fig. 4B) peaks at lower $G$, i.e. in $90<G<95 \mathrm{~mW} / \mathrm{cm}^{2}$ range which suggests that the most relevant $G$ is to be found below $100 \mathrm{~mW} / \mathrm{cm}^{2}$.

In order to precisely define the conditions which should be used to select the optimal resistor or diode we run a number of simulations which summarize one year energy yield for a typical DSSC aged under outdoor climate conditions $\left(G, T_{A I R}\right)$ if the cell is loaded with a certain resistor or a diode. In order to perform the simulations the (i) $I-V$ characteristics of DSSC for any given $T_{C}$ and $G$, (ii) the $T_{C}\left(T_{A I R}, G\right)$ dependence and (iii) a temperature dependence of a diode have to be modelled first.
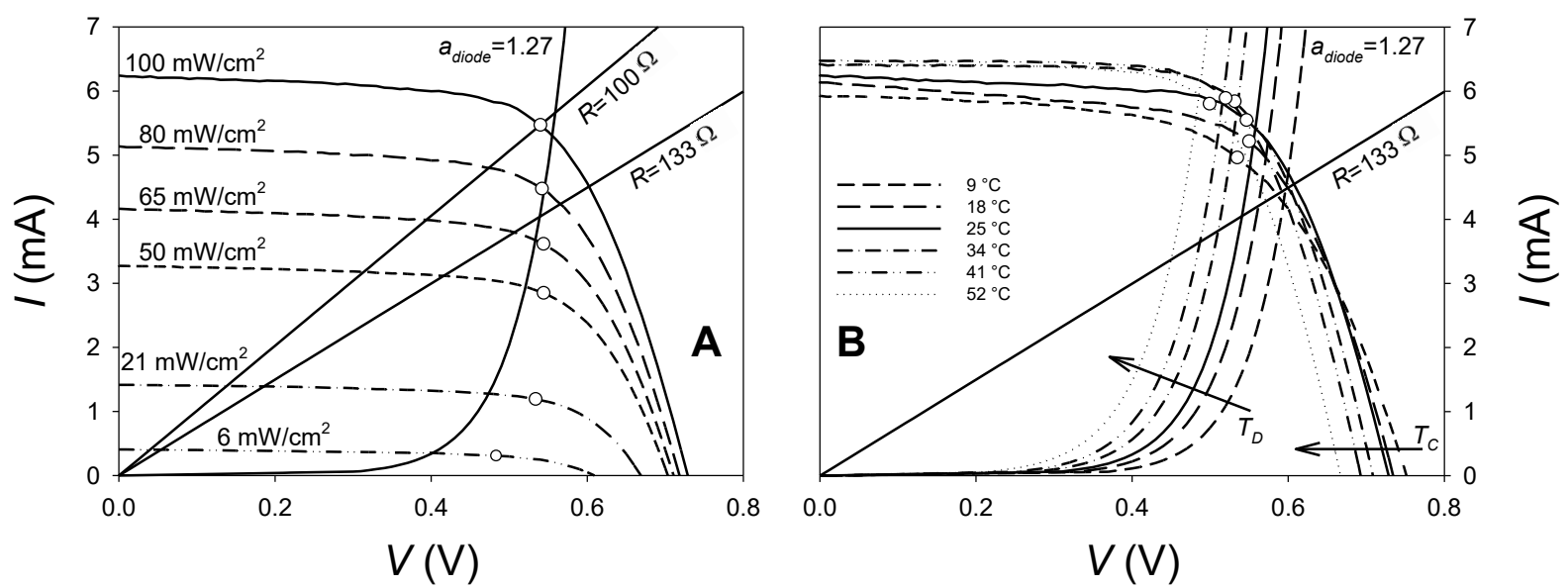

Fig. 5 The $I-V$ characteristics of the DSSCs $\left(A_{C E L L}=0.55 \mathrm{~cm}^{2}\right)$ measured at $T_{C}=25{ }^{\circ} \mathrm{C}$ and different $G(\mathrm{~A})$ and at $100 \mathrm{~mW} / \mathrm{cm}^{2}$ and different $T_{C}(\mathrm{~B})$. In addition the $I-V$ characteristics of the optimal resistor and a diode (for $T_{D}=T_{C}$ ) are given.

\subsubsection{Modelling the I-V characteristics of the DSSC}

The $I-V$ characteristics of the stable DSSC $\left(A_{C E L L}=0.55 \mathrm{~cm}^{2}\right)$ without any degradation measured at different $G$ and $T_{C}$ are shown in Figs. 5A and B, respectively. The behaviour is similar to other types of solar cells; the $V_{O C}$ logarithmically increases with increasing $G$ [31] and the $I_{S C}$ increases linearly (Fig. 5A) whereas the $V_{O C}$ linearly decreases with increasing $T_{C}$ due to more pronounced recombinations (Fig. 5B) [31, 32]. On the other hand the $I_{S C}\left(T_{C}\right)$ dependence of the DSSC slightly differs from other types of solar cells. The short-circuit current $\left(I_{S C}\right)$ of conventional c-Si solar cell increases with $T_{C}\left(0.06 \% /{ }^{\circ} \mathrm{C}\right)$ due to narrowing of the Si band-gap. This enhances the number of photons with sufficient energy to generate electron-hole pairs. On the other hand the $I_{S C}$ of the DSSCs initially increases with increasing $T_{C}$ till $41{ }^{\circ} \mathrm{C}$ since the diffusion of the $\mathrm{I}_{3}{ }^{-}$ions improves while a further increase in $T_{C}$ decreases the $I_{S C}$ due to more pronounced recombinations [32, 33].

All these $I-V$ characteristics (Fig. 5A and B) of one typical DSSC measured at different $G$ and $T_{C}$ were modelled with implicit $I-V$ equation, Eq. 1 [34] where the $I_{L}$ denotes photo-generated current, $I_{S}$ saturation current, $n$ diode ideality factor, $R_{S}$ serial resistance, $G_{S H}$ shunt conductance and thermal voltage $V_{T}=k \cdot T_{C} / q$ where $k$ denotes Boltzmann constant and $q$ elementary charge. Finally the $G$ and $T_{C}$ dependence of all five parameters $\left(I_{L}, I_{S}, n, R_{S}, G_{S H}\right)$ was empirically obtained and that allows us to determine $I-V$ characteristics of the DSSCs for any operating condition $\left(T_{C}, G\right)$. 
This is the accepted manuscript of the paper published in Solar Energy (Volume 135, October 2016, Pages 471-478), doi: 10.1016/j.solener.2016.06.014, C 2016 Elsevier Ltd.

$$
I(V)=I_{L}-I_{S}\left(e^{\frac{V+I \cdot R_{S}}{n \cdot V_{T}}}-1\right)-G_{S H} \cdot\left(V+I \cdot R_{S}\right) \quad 3.1 .2 \quad \text { Modelling of the }
$$

$T_{C}$

The $T_{C}$ of six DSSCs have been measured outdoor for approximately 7 months (AprilOctober). However, to determine the optimal resistor or diode over a year the modelling of the $T_{C}$ for the missing 5 months is required and needs to be simulated. The already existing temperature model of the solar cells, Eq. 2 [35] and 7 months measured data $\left(T_{C}, T_{A I R}\right.$ and $\left.G\right)$ have been used. The best results i.e. the most accurately predicted $T_{C}$ from the $T_{A I R}$ and $G$ measurements for the observed 7 months were achieved when $N=6$ (i.e. one hour running average of $G$ ) and $a=0.0296{ }^{\circ} \mathrm{C} / \mathrm{mW} / \mathrm{cm}^{2}$. The average $T_{C}$ error for the 7 months period is $2.3{ }^{\circ} \mathrm{C}$ which is reasonable accuracy especially since the $T_{C}$ has smaller effect on the MPP compared to $G$ (Fig. 5A and B). The model containing one hour running average of $G$ is justified since the cells were stored in a waterproof box during the ageing and that is also the reason why the cooling by the wind has a negligible effect on $T_{C}[35]$ and was thus excluded from the model. Finally the Eq. 2 with $N=6$ and $a=0.0296^{\circ} \mathrm{C} / \mathrm{mW} / \mathrm{cm}^{2}$ along with the outdoor measurements $\left(G, T_{A I R}\right)$ were used to define the missing $T_{C}$ while we used the measured $T_{C}$ if they were available.

$$
T_{C}(t)=T_{A I R}(t)+\frac{a}{N} \cdot \sum_{i=0}^{N} G(t-i \cdot 10 \mathrm{~min})
$$

\subsubsection{Model of the resistor and diode(s)}

The resistor was modelled according to Ohmic law without any temperature dependence since the resistors with negligible temperature coefficient are nowadays readily available. However most resistors have positive temperature coefficients while the solar cells have a negative temperature coefficient i.e. the voltage at the certain current decreases with increasing $T_{C}$. Therefore our simulation results regarding the MPP tracking with the resistor are rather idealized since we take into account temperature compensated resistor.

The loading by particular diodes that are used in our experiment was modelled according to Eq. 3 which includes two Schottky diodes (SD103) and a small shunt resistor $(R=1 \Omega)$ connected in serial (Fig. 2B). The $n$ in Eq. 3 denotes diode ideality factor, $V_{T}$ thermal voltage and $R$ a shunt resistor $(1 \Omega)$. The $I_{S}$ is a diode saturation current and is given by Eq. 4 where $A$ denotes cross-sectional area of the diode, $D_{p, n}$ are the diffusion coefficients of the holes and electrons, respectively, $N_{D, A}$ are the donor and acceptor concentrations at the $n$-side and $p$-side, respectively, $\tau_{p, n}$ are the carrier lifetimes of holes and electrons, respectively and $n_{i}$ the intrinsic carrier concentration in the semiconductor material.

The variation of the resistance in this theoretical study is simple and justified since a variety of resistors exist but this is not the case for the diodes. Although numerous diodes with different $I-V$ curves exist (i.e. different $I_{S}$ and $n$ ) it is practically difficult to find the diodes having exactly desired value. Therefore, in our theoretical study we introduced another dimensionless parameter, a diode area factor $a_{\text {diode }}(\mathrm{Eq} .4)$ which decreases $\left(a_{\text {diode }}<1\right)$ or increases $\left(a_{\text {diode }}>1\right)$ the diode's geometry and consequently linearly decreases or increases the $I_{\mathrm{S}}$ and diode's current $I$. This parameter has been used to simulate different hypothetical diodes to find the optimal value which would provide the most accurate annual MPP tracking. Variation of $a_{\text {diode }}$ could be justified since $A$ and $a_{\text {diode }}$ together define only a geometrical parameter that could be tuned in the manufacturing process of the optimal diode proposed by our study. 


$$
\begin{aligned}
& V=2 \cdot n(T) \cdot V_{T} \cdot \ln \left(\frac{I}{I_{S}(T)}+1\right)+R \cdot I \\
& I_{s}=a_{\text {diode }} \cdot A \cdot q \cdot\left(\sqrt{\frac{D_{p}}{\tau_{p}}} \cdot \frac{n_{i}^{2}}{N_{D}}+\sqrt{\frac{D_{n}}{\tau_{n}}} \cdot \frac{n_{i}^{2}}{N_{A}}\right)
\end{aligned}
$$

Accurate modelling of the load consisting diode(s) is also important since only the voltage drop on the $1 \Omega$ shunt resistor (Fig. 2B) can be periodically measured and afterwards the corresponding $I_{M P P}$ and $V_{M P P}$ are calculated using the Eqs. 3 and 4. Furthermore, in contrast to the resistor, the diodes are strongly temperature dependent which is described by the temperature dependence of the $n(T), I_{S}(T)$ and $V_{T}$ given by the manufacturer. The time dependent diode temperature $T_{D}$ was assumed equal to $T_{\mathrm{C}}$ in this study since diodes and DSSCs were placed close to each other in the water proof container.

As mentioned above two Schottky diodes (SD103) connected in serial were used since they have significantly lower "forward threshold voltage" (i.e. a virtual voltage where a diode start conducting) compared to ordinary Si $p n$-diodes therefore it is possible to track MPPs having only a few $\mathrm{mA}$ at around $0.5 \mathrm{~V}$. On the contrary, ordinary Si pn-diodes have significantly higher "forward threshold voltages" which can easily exceed even the $V_{O C}$ of the solar cells and as such are inappropriate for the MPP tracking. On the other hand the solar cells with significantly higher $V_{O C}$ and $V_{M P P}$ exist (e.g. perovskite absorber based solar cells). In this case ordinary Si $p n$-diodes or even three or more Schottky diodes connected in serial might provide optimal MPP tracking. Nevertheless, our theoretical study defines only the $I-V$ curve of the optimal diode while the user should either manufacture the optimal diode (e.g. by variation of the diode's geometry) or find the most appropriate combination of the available diode(s) as a passive load which altogether provide the best fit to the $I-V$ characteristic defined in this paper.

\subsubsection{Annual energy yield of the DSSC loaded with different resistors or diode(s)}

The measured or simulated $T_{C}$ along with measured $G$ in 10 min intervals were used to calculate the $I-V$ characteristics of the DSSC. The DSSC was loaded with a certain load (i.e. a resistor with a certain resistance or two Schottky diodes having a certain $a_{\text {diode }}$ ) which defined the operation conditions and the corresponding powers generated by the solar cell. These generated powers calculated in 10 min intervals were then integrated throughout the observed year and an annual energy yields were determined (i.e. energy production by the solar cell/energy consumption by the load). All these energy yields calculations including the $I-V$ modelling of the DSSC, $T_{C}\left(G, T_{A I R}\right)$ and the loads modelling were performed in Matlab.

The annual energy yields for different resistors and diodes are given in Figs. 6A and B, respectively. As a reference an annual energy yield is shown for the DSSC that is hypothetically connected to ideal MPP tracking device (dashed line). 

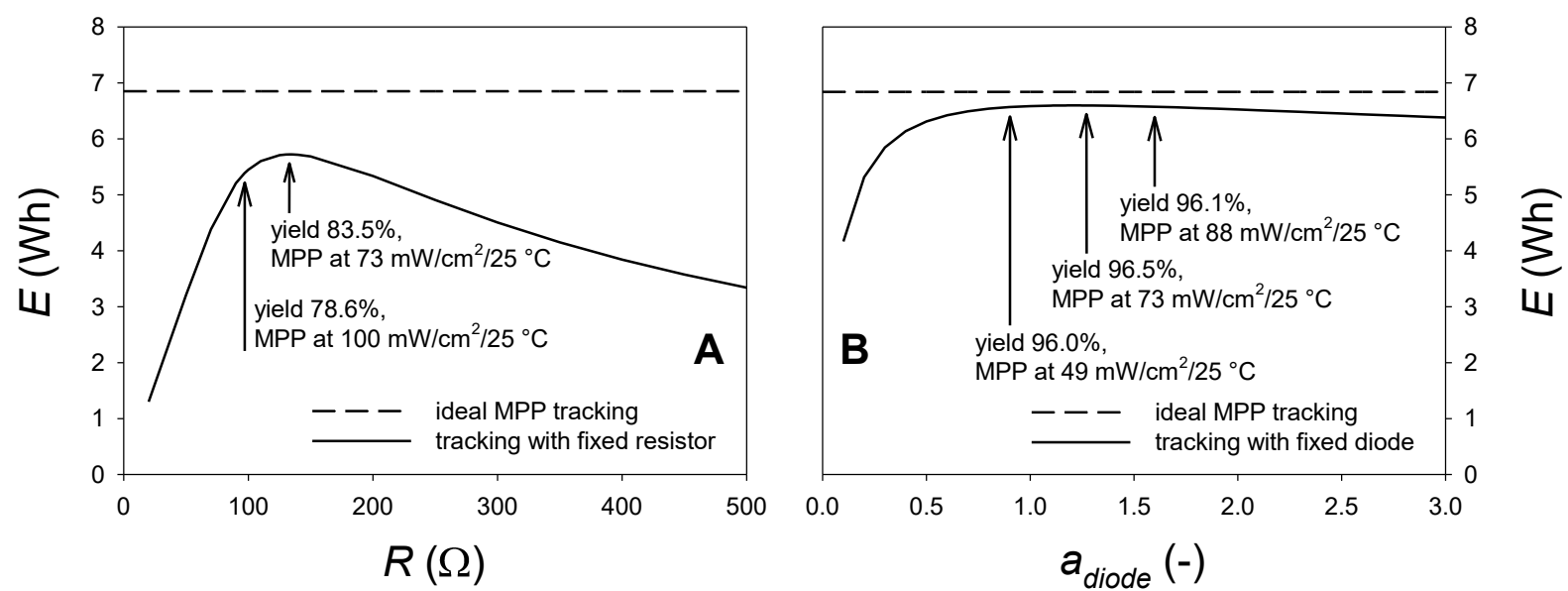

Fig. 6 The annual energy production of the DSSC loaded with different resistors (A) or diodes (B). As a reference an annual energy yield is shown for the DSSC that is connected to an ideal MPP tracking device (dashed line).

For our studied DSSC the potential annual energy yield in Ljubljana equals $6.85 \mathrm{Wh}$ $\left(A_{C E L L}=0.55 \mathrm{~cm}^{2}, \eta=5.4 \%\right)$ if an ideal MPP tracking device is used. On the other hand the DSSC generate as much as $83.5 \%$ of that energy although solely resistor $R=133 \Omega$ is connected to the solar cell. This optimal resistor can be determined from the MPP of the DSSC measured at $G=73 \mathrm{~mW} / \mathrm{cm}^{2}$ and $T_{C}=25^{\circ} \mathrm{C}$. However, the annual energy yield has well defined peak and a significant drop in the yield is observed if the $R$ is higher or lower than optimal value (Fig. 6A); the yield drops to $78.6 \%$ if the $R=97 \Omega$, i.e. the resistance that would provide MPP at STC. This resistor is evidently not appropriate for the outdoor ageing since the operating points are significantly shifted toward short-circuit condition at $G<100 \mathrm{~mW} / \mathrm{cm}^{2}$ (Fig. 5A). On the other hand the $R=133 \Omega$ perfectly matches the MPP at $G=73 \mathrm{~mW} / \mathrm{cm}^{2}$ and $T_{C}=25{ }^{\circ} \mathrm{C}$ while the operating points shifts toward open-circuit or short-circuit condition, respectively, if the $G$ is higher or lower than $73 \mathrm{~mW} / \mathrm{cm}^{2}$.

The energy yield is significantly higher when optimal diode is employed and it could reach $96.5 \%$ of the potential yield if a diode with $a_{\text {diode }}=1.27$ is used (i.e. a diode with $27 \%$ higher $I_{S}$ than the diode used in our experiment). This optimal $a_{\text {diode }}$ can be determined from the MPP measured at $G=73 \mathrm{~mW} / \mathrm{cm}^{2}$ and $T_{C}=25{ }^{\circ} \mathrm{C}$ as well as was true for the optimal resistor. The most interesting observation is the fact that the yield curve is relatively flat thus a variety of $a_{\text {diode }}(0.9$ to 1.6$)$ could be used to obtain more than $96 \%$ of the potential energy yield. In other words, the MPPs that are measured at $T_{C}=25^{\circ} \mathrm{C}$ and $49<G<88 \mathrm{~mW} / \mathrm{cm}^{2}$ can be used to choose almost optimal diode. Similarly as for the resistor also the $a_{\text {diode }}=1.27$ perfectly match the MPP at $G=73 \mathrm{~mW} / \mathrm{cm}^{2}$ and $T_{C}=25{ }^{\circ} \mathrm{C}$ while the operating point shifts toward open-circuit or short-circuit regime, respectively, if the $G$ is higher or lower than $73 \mathrm{~mW} / \mathrm{cm}^{2}$ (Fig. 5A).

Significantly better MPP tracking with an optimal diode is in agreement with the expectations since the $I-V$ characteristics of the optimal diode generally lies considerably closer to the MPP points of the solar cells measured at different $G$ than the $I-V$ characteristic of the ideal resistor (i.e. an optimal diode gives better load matching). Moreover, the passive load having identical characteristics as $I_{M P P}-V_{M P P}(G)$ characteristics of the solar cell would be even better (ideal) passive load for the MPP tracking. However, the $I_{M P P}-V_{M P P}(G)$ characteristic is usually multivalued (i.e. two different $I_{M P P}$ are possible at the same $V_{M P P}$ ) due to the nonlinear behaviour of the solar cells and due to $R_{S}$ and $G_{S H}$ influence. Therefore the idealised passive 
This is the accepted manuscript of the paper published in Solar Energy (Volume 135, October 2016, Pages 471-478), doi: 10.1016/j.solener.2016.06.014, C 2016 Elsevier Ltd.

loads for the MPP tracking are nearly impossible to manufacture and a certain approximation and optimization described in this paper is still needed.

Nevertheless, more evident presentation how different $T_{C}$ and $G$ influence the MPP tracking with the (realistic) optimal resistor or diode defined above is given in the following Section 3.2.
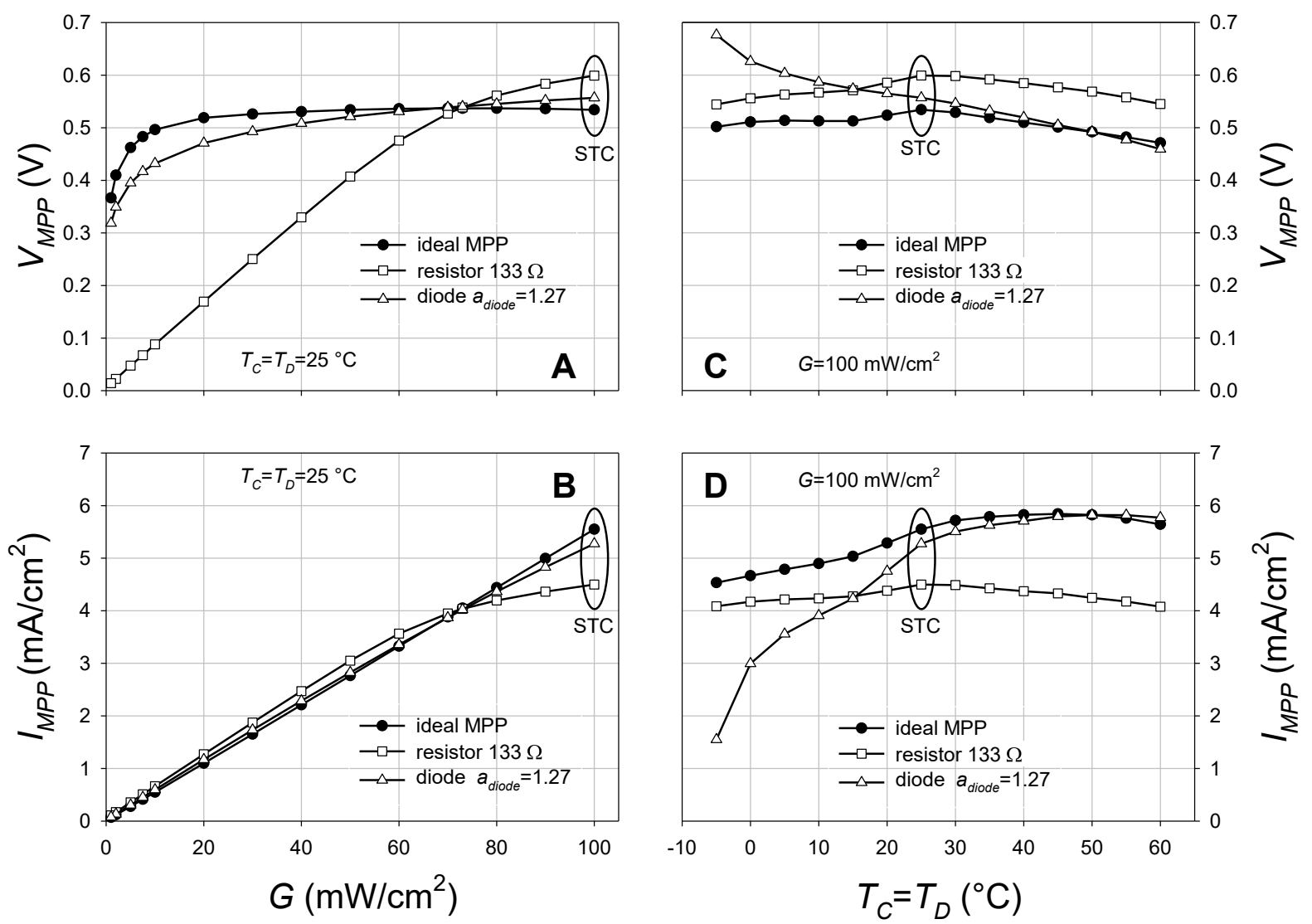

Fig. 7 A comparison of real $V_{M P P}(\mathrm{~A}, \mathrm{C})$ and $I_{M P P}(\mathrm{~B}, \mathrm{D})$ obtained for the DSSC at different $G$ $(\mathrm{A}, \mathrm{B})$ and $T_{C}(\mathrm{C}, \mathrm{D})$ with $V(\mathrm{~A}, \mathrm{C})$ and $I(\mathrm{~B}, \mathrm{D})$ obtained for the same DSSC under the same conditions but connected to optimal resistor or diode.

\subsection{Tracking error at different $G$ and $T_{C}$}

The optimal resistor or diode are used according to MPP measured at $73 \mathrm{~mW} / \mathrm{cm}^{2}$ at $25{ }^{\circ} \mathrm{C}$ therefore under this condition they both provide accurate $V_{M P P}$ and $I_{M P P}$ tracking (Fig. 7A and B). When a solar cell is loaded with the resistor and $G$ decreases $\left(G<73 \mathrm{~mW} / \mathrm{cm}^{2}\right)$ the operating point moves towards the short-circuit conditions (Fig. 5A) therefore the $I$ becomes slightly overestimated $\left(I>I_{M P P}\right)$, Fig. 7B. The opposite is true when $G$ is increased although a relative error is more pronounced (Fig. 7B). The shift of the operating condition with the $G$ affects especially the accuracy of $V_{M P P}$ tracking, Fig. 7A; the measured $V$ is slightly overestimated compared to real $V_{M P P}$ at $G>73 \mathrm{~mW} / \mathrm{cm}^{2}$ due to the shift toward open-circuit condition but it becomes significantly underestimated at $G<73 \mathrm{~mW} / \mathrm{cm}^{2}$ due to the shift toward short-circuit condition, e.g. at $G=10 \mathrm{~mW} / \mathrm{cm}^{2}$ the measured $V$ on resistor equals $0.1 \mathrm{~V}$ although the real $V_{M P P}$ equals $0.5 \mathrm{~V}$. On the other hand the exponential characteristic of the optimal diode closely follows the $V_{M P P}$ and especially the $I_{M P P}$ of the DSSC measured at different $G$ (Fig. 7A and B). Therefore the $V_{M P P}$ and $I_{M P P}$ tracking is significantly better over entire observed $G$ range $\left(0-100 \mathrm{~mW} / \mathrm{cm}^{2}\right)$, although some minor similar shifts of the operating 
condition (towards short-circuit condition at $G<73 \mathrm{~mW} / \mathrm{cm}^{2}$ or towards open-circuit condition at $G>73 \mathrm{~mW} / \mathrm{cm}^{2}$ ) could be observed as well.

The $T_{C}$ dependence of the DSSCs' parameters is more complex compared to $G$ dependence, Fig. 7C and D. Under this conditions the DSSCs loaded with the optimal resistor only provide better $I_{M P P}$ and $V_{M P P}$ tracking for the $T_{C}<15^{\circ} \mathrm{C}$, while the optimal diode still assures better tracking for higher $T_{C}$. Nevertheless, other solar cell technologies have usually less complex $T_{C}$ behaviour and a monotonic increase in the $I_{M P P}$ and monotonic decrease in the $V_{M P P}$ with increasing $T_{C}$ would be expected. Therefore the optimal diode is expected to follow the real MPP more accurately than the optimal resistor in general, especially if solar cell's $V_{M P P}$ variations with the $T_{C}$ are compensated by diode's voltage shifts due to simultaneous variations of the $T_{D}$.

\section{Conclusions}

In this study we developed the $I-V\left(G, T_{C}\right)$ and $T_{C}\left(G, T_{A I R}\right)$ models of ionic-liquid based dye-sensitized solar cell and used the annual outdoor data $\left(T_{C}, G\right)$ to calculate periodical $I-V$ characteristics for every 10 minutes. These $I-V$ characteristics were then used to calculate the annual energy production if the DSSC is loaded with different resistors or diodes in order to define the load which would provide the most efficient tracking to the solar cell's maximum-power-point (MPP). The most accurate tracking (i.e. the highest annual energy production of the solar cell or the highest energy consumption by the load) was achieved when the $I-V$ characteristic of the optimal resistor or diode crosses the MPP of the solar cell measured at $G=73 \mathrm{~mW} / \mathrm{cm}^{2}$ and $T_{C}=25^{\circ} \mathrm{C}$. The tracking is significantly better if a diode is used; the optimal diode consumes $96.5 \%$ of the energy that would be potentially produced annually by the solar cell connected to ideal MPP tracking device while the optimal resistor gets only $83.5 \%$ of that energy. Furthermore, a small variation in the resistance around optimal value significantly reduces the tracking efficiency while a broader assortment of diodes around optimal value still provides superior tracking.

\section{Acknowledgement}

The work was funded by the Slovenian Research Agency under the P2-0197 program.

\section{References}

[1] O’Regan, B., Grätzel, M., 1991. A Low-Cost, High-Efficiency Solar-Cell Based On Dye-Sensitized Colloidal $\mathrm{TiO}_{2}$ Films. Nature 353, 737-740.

[2] Hagfeldt, A., Boschloo, G., Sun, L., Kloo, L., Pettersson, H., 2010. Dye-Sensitized Solar Cells. Chem. Rev. 110, 6595-6663.

[3] Ye, M.D., Wen, X.R., Wang, M.Y., Iocozzia, J., Zhang, N., Lin, C.J., Lin, Z.Q., 2015. Recent advances in dye-sensitized solar cells: from photoanodes, sensitizers and electrolytes to counter electrodes. Mater. Today 18, 155-162.

[4] Sharifi, N., Tajabadi, F., Taghavinia, N., 2014. Recent Developments in Dye-Sensitized Solar Cells. ChemPhysChem 15, 3902-3927.

[5] Liu, Y., Zhao, J., Li, Z., Mu, C., Ma, W., Hu, H., Jiang, K., Lin, H., Ade, H., Yan, H., 2014. Aggregation and morphology control enables multiple cases of high-efficiency polymer solar cells. Nat. Commun. 5, 5293.

[6] Etxebarria, I., Ajuria, J., Pacios, R., 2015. Polymer: fullerene solar cells: materials, processing issues, and cell layouts to reach power conversion efficiency over $10 \%$, a review. J. Photon. Energy 5, 057214. 
This is the accepted manuscript of the paper published in Solar Energy (Volume 135, October 2016, Pages 471-478), doi: 10.1016/j.solener.2016.06.014, (c) 2016 Elsevier Ltd.

[7] Yan, J.F., Saunders, B.R., 2014. Third-generation solar cells: a review and comparison of polymer: fullerene, hybrid polymer and perovskite solar cells. RSC Advances 4, 43286-43314.

[8] Berginc, M., Opara Krašovec, U., Topič, M., 2014. Solution Processed Silver Nanoparticles in Dye-Sensitized Solar Cells. J. Nanomat. 2014, 357979.

[9] Spalatu, N., Hiie, J., Maticiuc, N., Krunks, M., Katerski, A., Mikli, V., Sildos, I., 2015. Plasmonic effect of spray-deposited $\mathrm{Au}$ nanoparticles on the performance of CSS CdS/CdTe solar cells. Appl. Surf. Sci. 350, 69-73.

[10] Yang, L., Pillai, S., Green, M.A., 2015. Can plasmonic Al nanoparticles improve absorption in triple junction solar cells?. Sci. Reports 5, 11852.

[11] Morawiec, S., Mendes, M.J., Filonovich, S.A., Mateus, T., Mirabella, S., Aguas, H., Ferreira, I., Simone, F., Fortunato, E., Martins, R., Priolo, F., Crupi, I., 2014. Broadband photocurrent enhancement in a-Si:H solar cells with plasmonic back reflectors. Opt. Express 22, A1059-A1070.

[12] Baek, S.W., Park, G., Noh, J., Cho, C., Lee, C.H., Seo, M.K., Song, H., Lee, J.Y., 2014. Au@Ag Core-Shell Nanocubes for Efficient Plasmonic Light Scattering Effect in Low Bandgap Organic Solar Cells. ACS Nano 8, 3302-3312.

[13] Yao, K., Salvador, M., Chueh, C.C., Xin, X.K., Xu, Y.X., deQuilettes, D.W., Hu, T., Chen, Y.W., Ginger, D.S., Jen, A.K.Y., 2014. A General Route to Enhance Polymer Solar Cell Performance using Plasmonic Nanoprisms. Adv. Eng. Mater. 4, 1400206.

[14] Liu, X.H., Hou, L.X., Wang, J.F., Liu, B., Yu, Z.S., Ma, L.Q., Yang, S.P., Fu, G.S., 2014. Plasmonic-enhanced polymer solar cells with high efficiency by addition of silver nanoparticles of different sizes in different layers. Sol. Energy 110, 627-635.

[15] Lu, Z.L., Pan, X.J., Ma, Y.Z., Li, Y., Zheng, L.L., Zhang, D.F., Xu, Q., Chen, Z.J., Wang, S.F., Qu, B., Liu, F., Huang, Y.D., Xiao, L.X., Gong, Q.H., 2014. Plasmonic-enhanced perovskite solar cells using alloy popcorn nanoparticles. RSC Adv. 5, 11175-11179.

[16] Kouhnavard, M., Ikeda, S., Ludin, N.A., Khairudin, N.B.A., Ghaffari, B.V., Mat-Teridi, M.A., Ibrahim, M.A., Sepeai, S., Sopian, K., 2014. A review of semiconductor materials as sensitizers for quantum dot-sensitized solar cells. Ren. Sust. Energy Rev. 37, 397-407.

[17] Labelle, A.J., Thon, S.M., Masala, S., Adachi, M.M., Dong, H.P., Farahani, M., Ip, A.H., Fratalocchi, A., Sargent, E.H., 2015. Colloidal Quantum Dot Solar Cells Exploiting Hierarchical Structuring. Nano Lett. 15, 1101-1108.

[18] Yang, W.S., Noh, J.H., Jeon, N.J., Kim, Y.C., Ryu, S., Seo, J., Seok, S.I., 2015. Highperformance photovoltaic perovskite layers fabricated through intramolecular exchange. Science 348, 1234-1237.

[19] Park, N.G., 2015. Perovskite solar cells: an emerging photovoltaic technology. Mater. Today $18,65-72$.

[20] Park, J.H., Seo, J., Park, S., Shin, S.S., Kim, Y.C., Jeon, N.J., Shin, H.W., Ahn, T.K., Noh, J.H., Yoon, S.C., Hwang, C.S., Seok, S.I., 2015. Efficient $\mathrm{CH}_{3} \mathrm{NH}_{3} \mathrm{PbI}_{3}$ Perovskite Solar Cells Employing Nanostructured p-Type NiO Electrode Formed by a Pulsed Laser Deposition. Adv. Mater. 27, 4013-4019.

[21] Snaith, H.J., 2013. Perovskites: The Emergence of a New Era for Low-Cost, HighEfficiency Solar Cells. J. Phys. Chem. Lett. 4, 3623-3630.

[22] Niu, G.D., Guo, X.D., Wang, L.D., 2015. Review of recent progress in chemical stability of perovskite solar cells. J. Mater. Chem. A 3, 8970-8980.

[23] Zhang, D.F., Zheng, L.L., Ma, Y.Z., Wang, S.F., Bian, Z.Q., Huang, C.H., Gong, Q.H., Xiao, L.X., 2015. Factors influencing the stability of perovskite solar cells. Acta Phys. Sinica 64, 038803.

[24] Leo, K., 2015. Perovskite Photovoltaics Signs of stability. Nat. Nanotech. 10, 574-575. 
[25] Li, X., Tschumi, M., Han, H.W., Babkair, S.S., Alzubaydi, R.A., Ansari, A.A., Habib, S.S., Nazeeruddin, M.K., Zakeeruddin, S.M., Grätzel, M., 2015. Outdoor Performance and Stability under Elevated Temperatures and Long-Term Light Soaking of Triple-Layer Mesoporous Perovskite Photovoltaics. Energy Tech. 3, 551-555.

[26] Berginc, M., Opara Krašovec, U., Topič, M., 2014. Outdoor ageing of the dye-sensitized solar cell under different operation regimes. Sol. Energy Mater. Sol. Cells 120, 491-499.

[27] Kamarzaman, N.A., Tan, C.W., 2014. A comprehensive review of maximum power point tracking algorithms for photovoltaic systems. Ren. Sust. Energy Rev. 37, 585-598.

[28] Lopez-Lapena, O., Penella, M.T., Gasulla, M., 2012. A Closed-Loop Maximum Power Point Tracker for Subwatt Photovoltaic Panels. IEEE Trans. Ind. El. 59, 1588-1596.

[29] Berginc, M., Topič, M., Opara Krašovec, U., 2014. Recovery of dye-sensitized solar cell's performance by heat treatment. Phys. Chem. Chem. Phys. 16, 12940-12948.

[30] Topič, M., Brecl, K., Sites, J.R., 2007. Effective efficiency of PV modules under field conditions. Prog. Photovolt. 15, 19-26.

[31] Berginc, M., Opara Krašovec, U., Topič, M., 2013. Evaluation of the recombination processes in DSSC by measuring the open circuit voltage over a wide illumination intensity range. Phys. Status Solidi A 210, 1750-1757.

[32] Berginc, M., Opara Krašovec, U., Jankovec, M., Topič, M., 2007. The effect of temperature on the performance of dye-sensitized solar cells based on a propyl-methylimidazolium iodide electrolyte. Sol. Energy Mater. Sol. Cells 91, 821-828.

[33] Berginc, M., Opara Krašovec, U., Hočevar, M., Topič, M., 2008. Performance of dyesensitized solar cells based on Ionic liquids: Effect of temperature and iodine concentration. Thin Solid Films 516, 7155-7159.

[34] Green, M.A., 1992. Solar Cells - Operating Principles, Technology and System Application. University of NSW, Kensington, Australia.

[35] Kurnik, J., Jankovec, M., Brecl, K., Topič, M., 2011. Outdoor testing of PV module temperature and performance under different mounting and operational conditions. Sol. Energy Mater. Sol. Cells 95, 373-376. 